\title{
Novel gastroretentive sustained-release tablet of tacrolimus based on self-microemulsifying mixture: in vitro evaluation and in vivo bioavailability test
}

\author{
Yan-ping WANG, Yong GAN, Xin-xin ZHANG* \\ Shanghai Institute of Materia Medica, Shanghai Institutes for Biological Sciences, Chinese Academy of Science, Shanghai 201203, \\ China
}

\begin{abstract}
Aim: To develop a novel gastroretentive drug delivery system based on a self-microemulsifying (SME) lipid mixture for improving the oral absorption of the immunosuppressant tacrolimus.

Methods: Liquid SME mixture, composed of Cremophor RH40 and monocaprylin glycerate, was blended with polyethylene oxide, chitosan, polyvinylpyrrolidone and mannitol, and then transformed into tablets via granulation, with ethanol as the wetting agent. The tablets were characterized in respect of swelling, bioadhesive and SME properties. In vitro dissolution was conducted using an $\mathrm{HCl}$ buffer at $\mathrm{pH}$ 1.2. Oral bioavailability of the tablets was examined in fasted beagle dogs.

Results: The tablet could expand to $13.5 \mathrm{~mm}$ in diameter and $15 \mathrm{~mm}$ in thickness during the initial 20 min of contact with the $\mathrm{HCl}$ buffer at $\mathrm{pH}$ 1.2. The bioadhesive strength was as high as $0.98 \pm 0.06 \mathrm{~N} / \mathrm{cm}^{2}$. The SME gastroretentive sustained-release tablets preserved the SME capability of the liquid SME formations under transmission electron microscope. The drug-release curve was fit to the zero-order release model, which was helpful in reducing fluctuations in blood concentration. Compared with the commercially available capsules of tacrolimus, the relative bioavailability of the SME gastroretentive sustained-release tablets was $553.4 \% \pm 353.8 \%$.

Conclusion: SME gastroretentive sustained-release tablets can enhance the oral bioavailability of tacrolimus with poor solubility and a narrow absorption window.
\end{abstract}

Keywords: immunosuppressants; tacrolimus; bioavailability; self-microemulsifying lipid mixture; gastroretentive sustained-release tablet

Acta Pharmacologica Sinica (2011) 32: 1294-1302; doi: 10.1038/aps.2011.90; published online 19 Sep 2011

\section{Introduction}

Tacrolimus, a 23-member macrolide lactone, was isolated from Streptomyces tsukubaensis early in $1984^{[1,2]}$. Its use is now well established for primary immunosuppression in liver and kidney transplantation. Meanwhile, experience with its use in other types of solid-organ transplantation, including heart, lung, pancreas and intestinal, as well as its use for the prevention of graft-versus-host disease in allogeneic bone marrow transplantation (BMT), is rapidly accumulating ${ }^{[3]}$. However, being a BCS class II drug, the clinical efficacy of tacrolimus is very limited because of its poor water solubility $(5-8 \mu \mathrm{g} / \mathrm{mL})$, which is responsible for its low oral bioavailability ${ }^{[2,4]}$. The dissolution rate of tacrolimus is one of the rate-limiting steps for its in vivo absorption. A self-microemulsifying drug delivery

\footnotetext{
* To whom correspondence should be addressed.

E-mail simm2122@vip.sina.com

Received 2011-01-18 Accepted 2011-05-25
}

system (SMEDDS) has been used to improve the oral bioavailability of poorly soluble drugs by presenting and maintaining the drug in a dissolved state during its entire transit through the gastrointestinal tract ${ }^{[5]}$. Therefore, SMEDDS was designed in this study to improve the dissolution and oral bioavailability of tacrolimus. At present, there are four drug products, Sandimmune $^{\circledR}$, Sandimmun Neoral ${ }^{\circledR}$ (cyclosporine A), Norvir ${ }^{\circledR}$ (ritonavir), and Fortovase ${ }^{\circledR}$ (saquinavir) on the pharmaceutical market, the active compounds of which have been formulated into the specific SMEDDS. Significant improvement in the oral bioavailability of these drug compounds has been demonstrated for each case, which further justifies this study ${ }^{[6]}$.

SMEDDS is usually formulated in a liquid form, which has some disadvantages, especially in the manufacturing process, leading to high production costs. Furthermore, incompatibility problems with the capsule shell are common ${ }^{[7]}$. Recently, with the development of new materials and a novel preparation process, there is growing interest in the study of solid self- 
microemulsifying drug delivery systems (S-SMEDDS) ${ }^{[5,7-14]}$. Compared with the traditional SMEDDS, S-SMEDDS can increase stability, extend storage time, reduce gastrointestinal irritation, and improve patient compliance. Furthermore, it was reported that the bioavailability of the self-microemulsifying mixture in a solid dosage form was equivalent to that of a liquid form ${ }^{[15]}$.

Similar to cyclosporin A, tacrolimus has a very narrow therapeutic window, and it exhibits large intra- and inter-individual variability of bioavailability, ranging from $4 \%$ to $89 \%$ (mean of around $25 \%)^{[16,17]}$. A high blood concentration will not only cause renal toxicity in the patient but also trigger the immune over-infection; however, a low concentration often leads to graft rejection. Post-treatment monitoring of blood levels is an integral part of patient care to maintain drug levels within the therapeutic range to optimize therapy and reduce undesirable toxic effects. This results in a significant inconvenience in the clinical application of tacrolimus. Therefore, designing a sustained-release formulation for tacrolimus that can control the drug blood concentration at a suitable level is quite essential. A tacrolimus sustained-release capsule developed by Astellas was approved both in Europe (Advagraf ${ }^{\circledR}$ ) and Japan $\left(\right.$ Graceptor $\left.^{\circledR}\right)$. In addition, Life Cycle Pharma A/S has developed a tacrolimus sustained-release tablet, and a clinical phase III trial is in progress ${ }^{[18]}$. Some in vitro and in vivo studies have shown that these formulations can reduce blood concentration fluctuations, and the differences in intra- and inter-individual levels have also been improved. However, these sustainedrelease capsules do not improve the bioavailability of tacrolimus, which is equivalent to the immediate-release capsules. The objective of developing SME sustained-release tablets in our study was not only to reduce the blood concentration fluctuations but also to improve the bioavailability.

Tacrolimus shows significant site dependence in intestinal permeability, and it is absorbed predominantly in the upper part of the small intestine ${ }^{[19,20]}$. It was reported that differences in P-gp and P450 function in each intestinal site could be a main cause of the site selectivity and large variability in tacrolimus absorption $^{[16]}$. The gastroretentive drug delivery system (GRDDS) is a preferable approach to improve the oral bioavailability and variability of a drug with a narrow absorption window in the upper part of the gastrointestinal tract (ie, stomach and small intestine). Prolonged gastric residence is expected to lead to an increased contact interval with the main absorption site of tacrolimus, the mucosa of the upper small intestine. Owing to its improved bioavailability combined with reduced frequency of administration and thus improved patient compliance, gastric retentive devices may also be used as extended-release drug delivery systems ${ }^{[21,22]}$. Several gastroretentive extended-release products are available on the market at present. Glumetza ${ }^{\circledR}$ (metformin hydrochloride) and Proquin $^{\circledR}$ XR (ciprofloxacin hydrochloride) extended-release tables were designed based on the mechanism of expansion and bioadhesion. They could release the drug in the upper gastrointestinal tract and showed higher plasma concentrations than the immediate-release formulation ${ }^{[23]}$. In this study, we developed tacrolimus solid SME sustained-release GRDDS combining the advantages of solid SME and sustained-release gastric retention agents to improve the bioavailability and reduce the blood concentration variability of tacrolimus.

\section{Materials and methods Materials}

Tacrolimus (FK506) was purchased from Zhejiang Laiyi Biotechnologies Co, Ltd. Monocaprylin glycerate (GMC) was a gift from Henan Zhengtong Chemical Co, Ltd (Zhengzhou, China). Polyoxyl 40 Hydrogenated Castor Oil (Cremophor RH40) was obtained from the BASF Corporation. Polyethylene oxide (PEO WSR N60K) was gifted from the DOW Chemical Company (Midland, MI, USA). Polyvinylpyrrolidone (PVP) K90 was gifted from the International Specialty Products (ISP) Corporation. Mannitol and chitosan (deacylation rate $\geq 90.0 \%$, viscosity=150 $\mathrm{mPa} \cdot \mathrm{s}$ ) were purchased from Shandong Jiejing Group Corporation (Rizhao, China) and Sinopharm Chemical Reagent Co, Ltd (Shanghai, China), respectively. The tacrolimus capsules: brand name Prograf; standard $1 \mathrm{mg} /$ tablet; batch number 1D5261A. All other chemicals were of reagent or HPLC grade. Deionized water was obtained from a Millipore ${ }^{\circledR}$ Milli-Q System (Molsheim, France) in the laboratory.

\section{Animals}

New Zealand rabbits (body weight $2.5 \pm 0.5 \mathrm{~kg}$ ) were obtained from the Medical Animal Test Center of the Shanghai Institute of Materia Medica (Shanghai, China). Six adult beagle dogs (three male and three female, average weight $8.6 \pm 1.5 \mathrm{~kg}$ ) were provided by the School of the Agriculture of Shanghai Jiao Tong University experiment and teaching practice field. License Nọ: SCXK (Shanghai) 27-0004. All experiments were performed according to the Shanghai Institute of Materia Medica guidelines for experimental animal care.

\section{Preparation of the solid-state self-microemulsifying dosage form} The solid self-microemulsifying drug delivery system (S-SMEDDS) of tacrolimus was prepared as follows: Cremophor RH40 and GMC at a ratio of 4:6 were accurately weighed into a glass vial, melted in a water bath at $40^{\circ} \mathrm{C}$ and mixed by a vortex to form a homogenous mixture. Tacrolimus was then dispersed into this mixture of oil and surfactant by vortex mixing and shaking at $37^{\circ} \mathrm{C}$ until a transparent solution of SMEDDS was obtained. Microemulsion adsorbed granular material was obtained from a mixture of SMEDDS solution, PEO N60K, PVP K90, mannitol and chitosan by constant stirring with ethanol as a wetting agent. The dried granules were lubricated with magnesium stearate and compressed into tablets on a single station tablet press (TDP-I, Shanghai Huamao Industrial \& Commercial Co, Shanghai, China).

The amounts of PEO, chitosan, mannitol and PVP added to the formulation to make one tablet containing $102 \mathrm{mg}$ of SMEDDS are listed in Table 1.

\section{Expanding study}

The swelling of the tablets can be measured by their abil- 
Table 1. Composition of the investigated tablets.

\begin{tabular}{lc}
\hline Ingredients & $\begin{array}{c}\text { Composition } \\
(\mathrm{mg} / \text { tablet })\end{array}$ \\
\hline Tacrolimus & 2 \\
GMC & 60 \\
Cremophor RH40 & 40 \\
Polyethylene oxide & 300 \\
Chitosan & 300 \\
Mannitol & 250 \\
Polyvinylpyrrolidone & 50 \\
\hline
\end{tabular}

ity to absorb water and the degree to which they swell. The swelling property of the formulation was determined by various techniques. Swelling index, water absorption rate and exposed size parameter are essential parameters to predict the gastroretentive performance of the expandable systems ${ }^{[24]}$. In this study, the exposed size parameter was chosen to measure the tablets' swelling. The water uptake study of the tablets was performed according to the Chinese Pharmacopoeia (CP) $\mathrm{XC}$ basket method. The medium used was $500 \mathrm{~mL}$ of an $\mathrm{HCl}$ buffer at $\mathrm{pH} 1.2$ rotated at 50 rotations per minute (r/min). The medium was maintained at $37 \pm 0.5{ }^{\circ} \mathrm{C}$ throughout the study. At a selected time interval, the tablets were withdrawn to measure their diameter and thickness.

\section{Bioadhesive strength study}

The adhesive strength of the tablets to rabbit stomach mucosa was evaluated using a self-made system with pallet scales. As shown in Figure 1, a hanging platform consisting of a cord and a glass slide attached with stomach mucosa was fixed to the pallet scales by a thick iron wire with a hook. A flat surfaced steel block was used as a lower static platform. The mucosa was mounted onto the lower platform using a medical rubber adhesive. The tablets were attached to the bottom of the hanging platform. The hanging platform with the tablets was

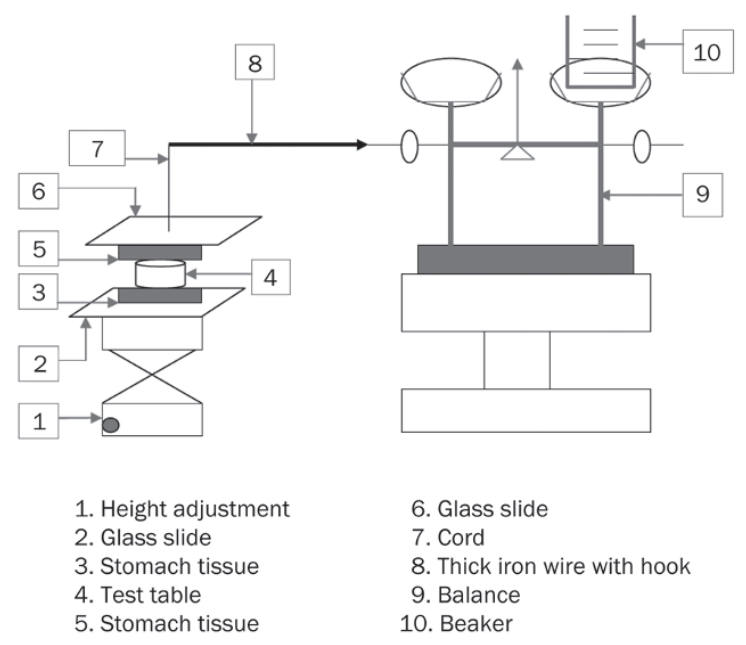

Figure 1. Schematic diagram of the bioadhesion testing device. brought down and placed over the surface of the mucosa with an applied force of $100 \mathrm{G}$ for $15 \mathrm{~min}$, and the force required to detach the tablets from the mucosal surface was determined by the weight of the added water. The test was performed at room temperature $\left(23-25^{\circ} \mathrm{C}\right)$, and the mean of the three measurements was used as the mucoadhesive strength of the tablets.

\section{Self-microemulsifying study}

To assess the self-microemulsifying properties, the tablet was introduced into $250 \mathrm{~mL}$ of $37^{\circ} \mathrm{C} \mathrm{HCl}$ buffer at $\mathrm{pH} 1.2$ under a gentle agitation of $50 \mathrm{r} / \mathrm{min}$ in a rotating basket dissolution apparatus. When the tablet was completely eroded, a sample was withdrawn and investigated using the transmission electron microscope (JEM-1230, JEOL, Japan). The sample was stained with phosphotungstic acid for visualization and placed on copper grids for viewing at $25 \pm 2{ }^{\circ} \mathrm{C}$. The droplet size distribution of the resultant emulsion was also determined by photon correlation spectroscopy (PCS) using a PSS Nicomp 380 ZLS (PSS Nicomp, Santa Barbara, CA, USA). Particle size distribution was expressed in a nicomp distribution. The sample was filtered through a $0.45-\mu \mathrm{m}$ micropore filter.

\section{Drug-release study}

Drug redispersibility and the release profiles of tacrolimus from the self-microemulsifying tablets and reference commercial immediate capsules were determined using the $\mathrm{CP} X \mathrm{C}$ rotating basket method (RCZ-8B dissolution tester, RZQ-8A automatic sampler, RDB-8A peristaltic pump, Tian Da Tian $\mathrm{Fa}$, Tianjin, China) at $37^{\circ} \mathrm{C}$. The rotating speed was $50 \mathrm{r} / \mathrm{min}$, and the dissolution medium was $900 \mathrm{~mL}$ of $\mathrm{HCl}$ buffer at $\mathrm{pH}$ 1.2 containing $0.005 \%(w / v)$ of hydroxypropylmethyl cellulose (HPC-M). Dissolution studies were conducted over $12 \mathrm{~h}$ to evaluate the sustained-release properties of the preparations.

Samples $(8 \mathrm{~mL})$ were withdrawn at predetermined time intervals and were assayed for tacrolimus by HPLC at $210 \mathrm{~nm}$. The HPLC system was composed of an autosampler (G1313A ALS), a pump (G1311 Quatpump), a column oven (G1316A Column), a UV detector (G1314A VWD) and data processing software (HP Chemstation Rev.A.10.01). Briefly, tacrolimus was analyzed using Agilent Zorbax XDB C8 (150×4.6 mm, 5 $\mu \mathrm{m})$ a reverse phase chromatography column. The mobile phase consisted of acetonitrile- $0.25 \%$ phosphoric acid (65:35, $v / v$ ) and was pumped at a flow rate of $1.0 \mathrm{~mL} / \mathrm{min}$.

In vitro release data of the sustained-release tablets were analyzed using the zero-order release model $(Q=k t)$, Higuchi model $\left(Q=k t s^{1 / 2}\right)$ and the first-order release model [ $\ln (100$ $Q)=\ln 100-k t]$, where $Q$ is the percentage of drug released at $t$ time and $k$ is the release rate constant.

\section{In vivo pharmacokinetics study in beagle dogs}

Six healthy beagle dogs that had fasted but had free access to water for $12 \mathrm{~h}$ prior to the experiment were used in this study. They were allocated at random to two treatment groups and were orally administered gastroretentive tablets and two reference commercial capsules of tacrolimus once a day in a cross- 
over design with a 1-week washout period between dosing. The dose of tacrolimus administered was $2 \mathrm{mg}$.

At a predetermined time interval, a blood sample $(3.0 \mathrm{~mL})$ was withdrawn at $0,1,2,4,6,8,10,12,24$, and $36 \mathrm{~h}$ for the gastroretentive tablet group and $0.5,1,1.5,2,3,4,6,8,10,12$, and $24 \mathrm{~h}$ for the reference capsule group. Blood samples collected from the thigh vein were syringed into centrifuge tubes containing heparin and then kept frozen at $-20{ }^{\circ} \mathrm{C}$ until analysis. The tacrolimus concentrations in the whole blood samples were determined by high performance liquid chromatography mass spectrometry (HPLC-MS) with a low quantitation limit of $0.2 \mathrm{ng} / \mathrm{mL}$.

A selective, rapid and sensitive HPLC-MS method was developed for the quantification of tacrolimus in dog whole blood. A two-step liquid-liquid extraction was included in the sample pretreatment. Then, $1 \mathrm{~mL}$ of a $70 \%$ acetonitrile solution was added to $1 \mathrm{~mL}$ of the whole blood. After vortex mixing for $30 \mathrm{~s}, 4 \mathrm{~mL}$ of dichloromethane solution containing $1 \%$ isoamyl alcohol was added and vortexed for $15 \mathrm{~min}$. After centrifugation at $4000 \mathrm{r} / \mathrm{min}$ for $10 \mathrm{~min}$, the lower organic phase was collected, and the residue was extracted with $4 \mathrm{~mL}$ of dichloromethane solution containing $1 \%$ isoamyl alcohol. The lower organic phase was combined and dried under nitrogen gas at $70^{\circ} \mathrm{C}$. The residue was reconstituted with $200 \mu \mathrm{L}$ of the mobile phase. Separation was carried out on an AlltechAlltima $^{\text {TM }}-\mathrm{C} 18$ column $(150 \mathrm{~mm} \times 2.1 \mathrm{~mm}, 3 \mu \mathrm{m})$ with methanol as the mobile phase at a flow rate of $0.2 \mathrm{~mL} / \mathrm{min}$.

Detection was performed by a Thermo Finnigan LTQ HPLCMS (Thermo Finnigan, USA). The mass spectrometer was operated with an electrospray ionization (ESI) interface in positive ionization mode and with multiple-reaction monitoring mode. The selected reaction monitoring (SRM) of tacrolimus was $m / z$ 826.48. The concentration of tacrolimus was determined by a standard linear calibration curve in the concentration range of $0.2-20 \mathrm{ng} / \mathrm{mL}$.

The maximum whole blood concentration $\left(C_{\max }\right)$, time to $C_{\max }\left(t_{\max }\right)$, and the area under the whole blood concentration versus time curve (AUC) were calculated from observed data points with the Drug and Statistics (DAS 2.1.1) pharmacokinetic software. Statistical analysis $\left(C_{\max }, t_{\max }\right.$ AUC) was also conducted with the DAS 2.1.1 software. The relative bioavailability (F) of the gastroretentive tablet to the commercial capsule (reference) was calculated using the following equation:

$$
\mathrm{F}=\frac{\mathrm{AUC}_{\text {test }}}{\mathrm{AUC}_{\text {reference }}} \times 100 \%
$$

\section{Statistical analysis}

Results are expressed as the mean \pm standard deviation. Statistical comparisons were performed using a bilateral $t$-test $\left(C_{\max }\right.$, AUC) and a non-parametric test $\left(t_{\max }\right)$ with the DAS 2.1.1 software. A $P$ value $<0.05$ was considered statistically significant.

\section{Results}

\section{Development of the tablet}

Self-microemulsifying systems form fine oil-water emulsions with only gentle agitation upon their introduction into aqueous media. Therefore, the selection of the oil, surfactant, and mixing ratio play an important role in the formulation of the microemulsion. In the present study, Cremophor RH40 and GMC were tested for phase behavior. The influence of the oil and surfactant ratio on the particle size distribution was evaluated. As seen in Figure 2, Cremophor RH40 gave a wide microemulsion region. Increasing the oil ratio resulted in a larger particle size. Cremophor RH40 and monocaprylin glycerate at a ratio of $4: 6$ have the optimal particle size distribution, so it was selected for the formulation study.

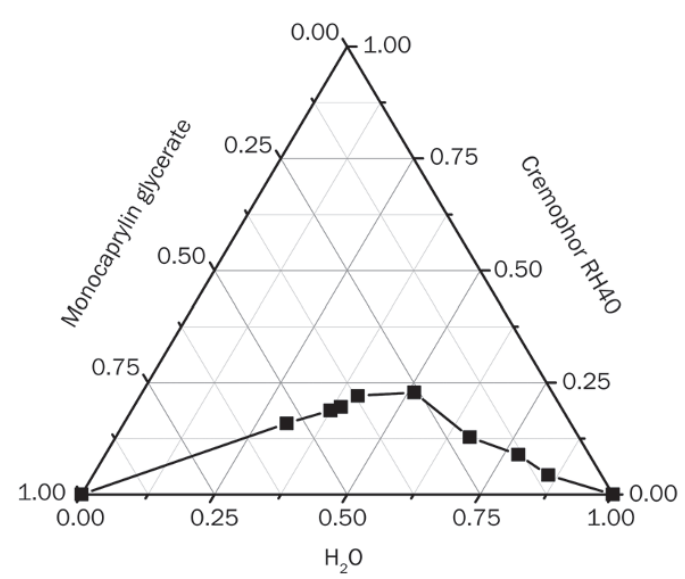

\begin{tabular}{lccc}
\hline $\begin{array}{l}\text { Formu- } \\
\text { lation }\end{array}$ & $\begin{array}{c}\text { Cremophor RH40: } \\
\text { Monocaprylin } \\
\text { glycerate }\end{array}$ & $\begin{array}{c}\text { Mean particle } \\
\text { size }(\mathrm{nm})\end{array}$ & $\begin{array}{c}\text { Polydispersity } \\
\text { index }\end{array}$ \\
\hline S1 & $8: 2$ & $15.1 \pm 1.5$ & $0.21 \pm 0.02$ \\
S2 & $6: 4$ & $24.3 \pm 2.1$ & $0.38 \pm 0.047$ \\
S3 & $4: 6$ & $25.9 \pm 2.3$ & $0.04 \pm 0.007$ \\
S4 & $3: 7$ & $44.4 \pm 2.8$ & $0.28 \pm 0.032$ \\
S5 & $2: 8$ & $104.6 \pm 3.6$ & $0.44 \pm 0.051$ \\
\hline
\end{tabular}

Figure 2. Phase diagram and particle size distribution of SMEDDS containing Cremophor RH40 and monocaprylin glycerate.

On the basis of previous studies on the swelling properties of matrix tablets, we concluded that the polyethylene oxide (PEO) polymer is an excellent vehicle for swelling tablets ${ }^{[25-27]}$. Earlier studies have demonstrated that PEO also has good adhesion. Therefore, PEO was chosen as the skeleton material of the tablet, which provided swelling and adhesion capability for the tablet. PVP is a nonirritant material that is extensively used as a tablet binder ${ }^{[27]}$. It is well known that the expanded form must maintain its integrity and have adequate strength to withstand the force in the stomach ${ }^{[28]}$. Moreover, the high molecular weight grades of PVP offer higher binding capacity. Therefore, PVP K90 was introduced as a tablet binder and was simultaneously used to increase the ability of the resistance to the gastric motility of the swelling tablet.

The goals of gastric retention and controlling release are not 
always compatible. PEO is a matrix material that possesses the characteristics of both swelling and controlling release; however, PEO takes a very long time to completely erode when it is used at the amount needed for sufficient swelling to achieve gastric retention. Some other matrix materials can also swell but offer the benefit of faster and more even erosion in the gastric environment, which means that the dosage form made with these materials can pass through the gastrointestinal tract more predictably after a few hours of drug release. One such material is chitosan, which swells, but not to the same degree as PEO. Chitosan can generate synergies with PEO in the expansion of matrix tablets, and the releases that are controlled by the erosion of the polymeric matrix are also easier. Moreover, chitosan also has very strong adhesion, which has a prominent role in enhancing the adhesion force of the tablet. Hence, we developed a PEO and chitosan combination gastric retention tablet, which not only maintained good swelling of the tablets but also insured that the tablets completely eroded at the scheduled time, taking double advantage of the chitosan. In this study, mannitol was used to further regulate the drug-release rate.

\section{Expanding study}

It is reported that the dosage form size has a great influence on its residual effects in the stomach. Due to the retropulsion reflex, gastroretentivity may simply be achieved by large dimensions that are physically unable to pass through the pyloric sphincter ${ }^{[29]}$. The pyloric sphincter has a diameter of $12.8 \pm 7 \mathrm{~mm}$ in humans ${ }^{[29]}$. To achieve a size adequate for preventing passage through the pylorus yet small enough to be swallowed requires very significant expansion in at least two dimensions ${ }^{[28]}$. The tablet we developed expanded to 13.5 $\mathrm{mm}$ in diameter and $15 \mathrm{~mm}$ in thickness after $20 \mathrm{~min}$, and then to $16 \mathrm{~mm}$ in diameter and $20 \mathrm{~mm}$ in thickness after $3 \mathrm{~h}$ of contact with an $\mathrm{HCl}$ buffer at $\mathrm{pH}$ 1.2. The two dimensions of the size of the tablet at different times are shown in Figure 3. The results revealed that the tablet swelled rapidly when immersed in the $\mathrm{HCl}$ buffer at $\mathrm{pH} 1.2$, and the tablet maintained this large size for at least $8 \mathrm{~h}$. These results indicated that the tablet had a very good capacity to improve the effec-

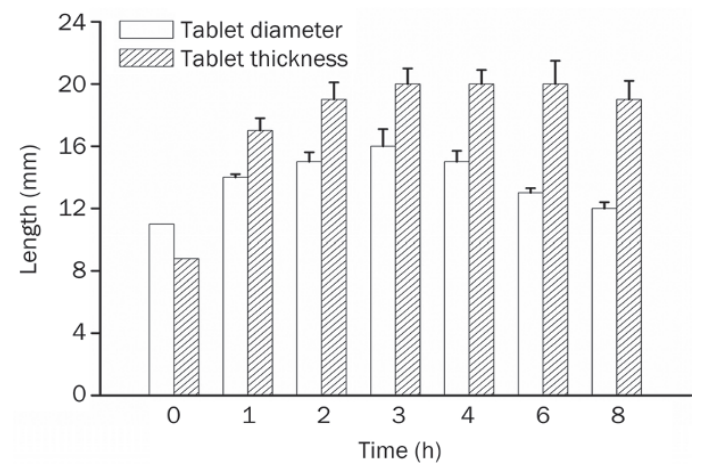

Figure 3. Gel layer diameter and thickness of the self-microemulsifying gastroretentive sustained-release tablets during contact with the $\mathrm{HCl}$ buffer at $\mathrm{pH}$ 1.2. $n=6$. Mean \pm SD. tiveness of gastric retention.

\section{Bioadhesive strength study}

Gastroretention can be achieved by the swelling property of the tablet, and bioadhesion may be an important property for further strengthening of the gastroretentive feature of tablets. PEO polymers are reported to have potential bioadhesive properties. To reinforce the mucoadhesion feature, chitosan, which is widely used as a bioadhesive polymer, was added to the formulation. Its mucoadhesive properties are mediated by ionic interactions of the positively charged amino groups and negatively charged substructures of the gastrointestinal mucus, mainly sialic acid ${ }^{[30]}$. The dissolution time and bioadhesion force with and without chitosan are shown in Table 2. As depicted in Table 2, the result of the bioadhesion study indicated that chitosan had a more significant effect than PEO on bioadhesion. This may be due to different adhesion mechanisms in PEO and chitosan, which resulted in different contributions to the adhesion of the tablet. Moreover, tablets with chitosan took less time to completely erode. The bioadhesive strength of PEO N60K tablet with chitosan was $0.98 \pm 0.06$ $\mathrm{N} / \mathrm{cm}^{2}$, which ensured that the tablet could adhere to the gastric mucosa.

Table 2. Bioadhesion and time for $95 \%$ drug release of PEO tablets. $n=6$. Mean \pm SD.

\begin{tabular}{llcc}
\hline Code $^{\#}$ & \multicolumn{1}{c}{ Composition } & $\begin{array}{c}\text { Bioadhesion } \\
\left(\mathrm{N} / \mathrm{cm}^{2}\right)\end{array}$ & $\begin{array}{c}\text { Time for 95\% } \\
\text { drug release }(\mathrm{h})\end{array}$ \\
\hline 1 & PEO 600 mg & $0.81 \pm 0.09$ & $21.8 \pm 1.2$ \\
2 & PEO 300 mg+Chitosan 300 mg & $0.98 \pm 0.06$ & $12.1 \pm 0.8$ \\
\hline
\end{tabular}

PEO, polyethylene oxide. Formation \#1 and \#2 also include $2 \mathrm{mg}$ tacrolimus, $60 \mathrm{mg}$ monocaprylin glycerate, $40 \mathrm{mg}$ Cremophor RH40, 250 mg mannitol, 50 mg polyvinylpyrrolidone.

\section{Self-microemulsifying study}

The incorporation of the self-microemulsifying mixture into a solid dosage form is desirable, but challenging, because selfmicroemulsifying properties are harder to achieve with solid materials ${ }^{[7]}$. Therefore, it is necessary to determine whether or not the tablet that is composed of a self-microemulsifying mixture and solid materials can self-microemulsify when it contacts water or SGF. The droplet size nicomp distribution of the liquid SMEDDS and solid SMEDDS are shown in Figure 4. The average dispersing droplet size of the liquid SMEDDS and solid SMEDDS were $28.9 \mathrm{~nm}$ and $26.2 \mathrm{~nm}$, respectively. These results indicated that the solid self-microemulsifying formulation (SMEF) preserved the self-microemulsification performance of the liquid SMEF. TEM (Figure 5) showed that the reconstituted microemulsions were released from the solid SMEF when exposed to SGF. The size range was narrow, and the droplet size was very small (approximately 


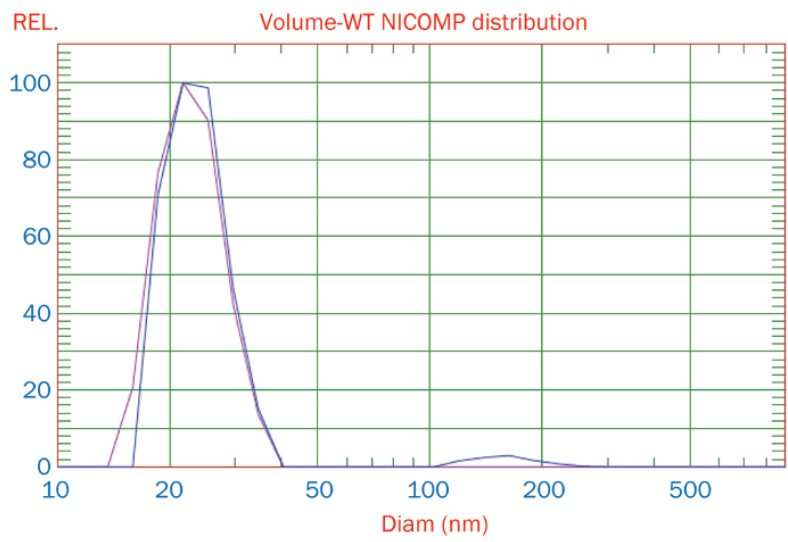

Figure 4. Microemulsion droplet size distribution: solid SMEDDS (blue line); liquid SMEDDS (red line).

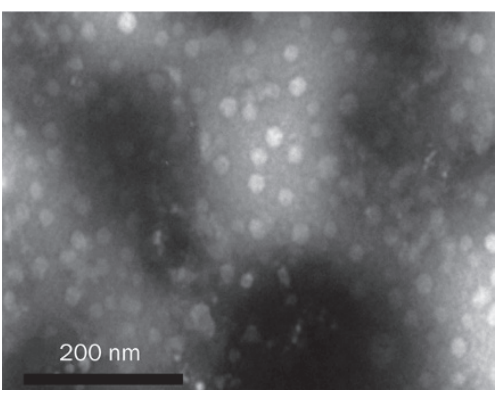

Figure 5. Transmission electron micrograph of the reconstituted microemulsion released from the gastroretentive sustained-release tablet.

20-30 nm). These results were consistent with the results of the PCS analysis. TEM showed the quality of the microemulsion that was formed. Emulsion droplet size is a decisive factor in self-microemulsifying formulation performance because it determines the rate and the extent of drug release. Smaller droplet size improves the drug release and provides a larger interfacial area across which the drug can diffuse into the gastrointestinal fluids, and thus, it increases drug absorption ${ }^{[31,32]}$. TEM and nicomp distribution results confirmed that the tablet could self-microemulsify in the gastrointestinal tract, and the droplet size of the emulsion drops was small, which could achieve the purpose of increasing drug solubility and improving drug absorption.

\section{Drug-release study}

For drug candidates with lower aqueous solubility, the drugrelease rate is dependent mainly on the erosion of the polymeric matrix ${ }^{[33,34]}$. As demonstrated in Figure 6, about $100 \%$ of the tacrolimus is released within $2 \mathrm{~h}$ from the commercial capsules. In contrast, for the tacrolimus self-microemulsifying gastroretentive sustained-release tablets, the concentration of drug released was very low within two hours, and almost no drug was released in the first hour. This was because the matrix swelling was much faster compared with the erosion

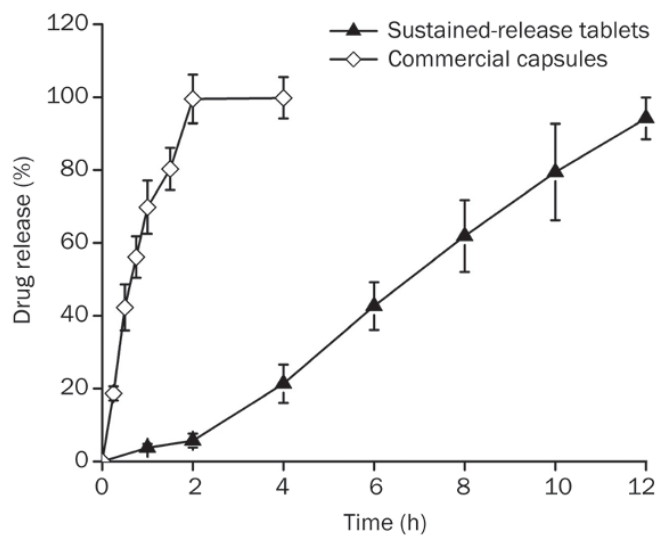

Figure 6. Dissolution profiles of tacrolimus from the sustained-release self-microemulsifying gastroretentive tablets and the commercial immediate-release capsules. ( $2 \mathrm{mg}$ tacrolimus; $n=6$, arithmetic mean \pm SD).

process during the initial contact with the dissolution medium; therefore, matrix erosion did not occur during this time.

The fitting equations of the drug-release curve are shown in Table 3. According to the correlation coefficient of the fitting curve, the release curve was fit to the zero-order release model, which was helpful in reducing fluctuations in blood concentrations. The release mechanism of tacrolimus from the $\mathrm{PEO}$, chitosan and mannitol coupling gastric retention matrix tablets was mainly based on erosion.

Table 3. The release pattern of tacrolimus self-microemulsifying sustained release tablets.

\begin{tabular}{llll}
\hline $\begin{array}{l}\text { Release } \\
\text { pattern }\end{array}$ & \multicolumn{1}{c}{ Fitting equation } & $R^{2}$ & Adj $R^{2}$ \\
\hline Zero order & $Q=8.70426 t-9.30741$ & 0.9938 & 0.9925 \\
First order & $\operatorname{Ln}(100-Q)=-0.23325 t+5.13975$ & 0.8768 & 0.8522 \\
Higuchi & $Q=38.55712 t^{1 / 2}-45.72334$ & 0.9586 & 0.9503 \\
\hline
\end{tabular}

\section{In vivo pharmacokinetics study in beagle dogs}

Mean whole blood levels of tacrolimus at each time point are summarized in Figure 7. From Table 4, it can be seen that the $\mathrm{AUC}_{(0-\infty)}$ was approximately five times greater when tacrolimus was administered as gastroretentive tablets as compared to the commercial capsules. The mean value of $C_{\max }$ for the gastroretentive tablets $(8.86 \mathrm{ng} / \mathrm{mL})$ was 2.3 times greater than the $C_{\max }$ obtained with the same dose of tacrolimus administered as the commercial capsules $(3.78 \mathrm{ng} / \mathrm{mL})$. Gastroretentive tablets resulted in an average $t_{\max }$ of $6.67 \mathrm{~h}$, which was obviously longer than the $t_{\max }$ of the commercial capsules $(1 \mathrm{~h})$. The gastroretentive tablets resulted in a significant absorption of tacrolimus compared to the commercial capsules $(P<0.05)$. 
Table 4. Pharmacokinetic parameters of tacrolimus from self-microemulsifying gastricretentive sustained release tablets and commerical capsules.

\begin{tabular}{|c|c|c|c|c|c|c|c|c|c|c|}
\hline \multirow{2}{*}{ № } & \multirow{2}{*}{$\begin{array}{c}\text { Order of } \\
\text { administration }\end{array}$} & \multicolumn{2}{|c|}{$A U C_{(0-t)}\left(n g \cdot h \cdot m L^{-1}\right)$} & \multicolumn{2}{|c|}{$A \cup C_{(0-\infty)}\left(\mathrm{ng} \cdot \mathrm{h} \cdot \mathrm{mL}^{-1}\right)$} & \multicolumn{2}{|c|}{$t_{\max }(\mathrm{h})$} & \multicolumn{2}{|c|}{$C_{\max }\left(n g \cdot \mathrm{mL}^{-1}\right)$} & \multirow{2}{*}{$\mathrm{F} \%$} \\
\hline & & $\mathrm{SEGT}^{\mathrm{a}}$ & $\mathrm{CC}^{\mathrm{b}}$ & SEGT & $\mathrm{CC}$ & SEGT & $\mathrm{CC}$ & SEGT & $\mathrm{CC}$ & \\
\hline 2 & SMEGSRT/CC & 206.91 & 18.67 & 252.52 & 25.68 & 8 & 1 & 11.54 & 2.50 & 1107.8 \\
\hline 3 & SMEGSRT/CC & 74.48 & 43.99 & 85.39 & 68.74 & 6 & 1 & 6.02 & 5.01 & 169.3 \\
\hline 4 & CC/SMEGSRT & 209.91 & 32.11 & 320.47 & 48.21 & 10 & 1 & 11.23 & 3.98 & 653.7 \\
\hline \multirow{2}{*}{6} & Mean & 142.76 & 29.16 & 192.25 & 42.00 & 6.67 & 1 & 8.86 & 3.78 & 553.4 \\
\hline & $\mathrm{SD}$ & 67.12 & 8.51 & 99.23 & 15.10 & 2.42 & 0 & 2.38 & 1.02 & 353.8 \\
\hline
\end{tabular}

${ }^{\text {a }}$ SMEGSRT self-microemulsifying gastricretentive sustained release tablets.

${ }^{\mathrm{b}} \mathrm{CC}$ commercial capsules.

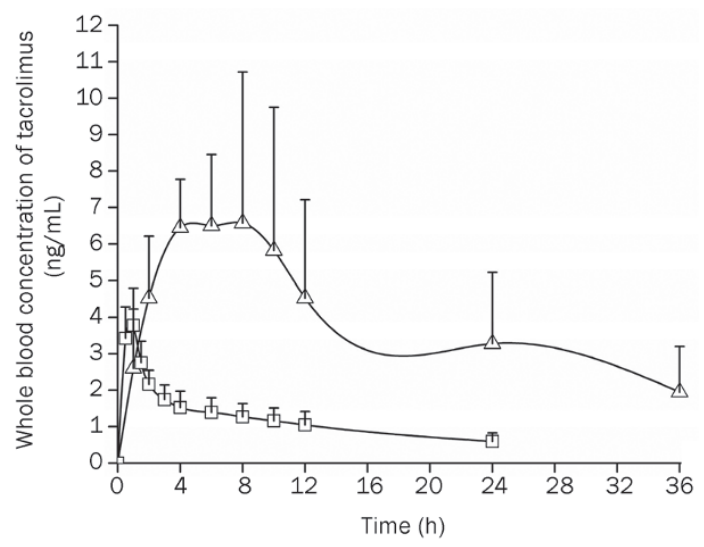

Figure 7. Whole blood concentration versus time curve (arithmetic mean $\pm S D, n=6$ ) of tacrolimus ( $2 \mathrm{mg}$ per dog) in beagle dogs after oral administration of the self-microemulsifying gastroretentive sustainedrelease tablets $(\Delta)$ or commercial capsules $(\square)$.

\section{Discussion}

There is a clear pharmaceutical need for advanced delivery systems that continuously supply drugs with narrow absorption window to their absorption site for an extended time period. This approach would provide effective and sustained drug concentrations in the blood for prolonged periods of time. It would also eliminate the need for frequent drug administration and the use of inconvenient modes of administration. This is particularly true for tacrolimus to prolong the release of drug in the duodenum by a gastroretentive dosage form (GRDF).

The current investigation presents a novel and promising sustained-release GRDF based on the combination of large dimensions, bioadhesive strength, sustained release of the loaded drug and self-microemulsification. In this study, the sustained-release GRDF of tacrolimus was prepared using a combination of PEO and chitosan as a solid carrier. The SME gastroretentive sustained-release tablets preserved the selfmicroemulsification performance of the liquid SMEDDS. The optimized formulation followed zero-order release kinetics. Swelling studies indicated significant water uptake and swelling, which may be significant in gastroretention. The bioadhesive properties were also studied, and the developed formulation showed significant bioadhesion. Thus, by combining these approaches of gastroretention together, the in vivo gastroretention could be predicted more reliably. Based on these promising in vitro results, in vivo studies in beagle dogs were carried out to determine various pharmacokinetic parameters. The relative oral bioavailability of the model drug, tacrolimus, was 5.5-fold compared to the commercial capsules. Gastroretentive tablets resulted in an average $t_{\max }$ of $6.67 \mathrm{~h}$, which was obviously longer than the $t_{\max }$ obtained from the commercial capsules (1 h).

The higher bioavailability of hydrophobic drugs incorporated in a SMEDDS has been reported elsewhere ${ }^{[35-37]}$. The contribution of the GRDF approach extended the length of the absorption phase in comparison with the non-gastroretentive dosage form. This allows the desired therapeutic concentration to be achieved for prolonged periods of time. Thus, a combination of SMEDDS and GRDF can usually further improve the bioavailability of drugs. However, in terms of some rapid metabolism of drugs in the gastrointestinal tract, GRDF, which inputs the drug into the intestinal epithelial cells with the sustained mode, may enhance the efficacy of first pass metabolism in the intestinal wall. This phenomenon may reduce the bioavailability of drugs in some cases. Therefore, whether the sustained-release gastroretentive tablets can enhance the bioavailability of self-microemulsifying agents needs further study according to the specific absorption and metabolism characteristics of drugs.

Several factors have been suggested as possible determinants of the low oral bioavailability of tacrolimus. These include a low solubility in the intestine, extensive metabolism by CYP3A4 in the gut, and P-gp-mediated drug efflux. Regional differences in the functional expression of P-gp were investigated in the human intestine, indicating that there is higher activity of P-gp in the ileum and the colon than in the jejunum ${ }^{[16]}$. Therefore, the sustained-release gastroreten- 
tive tablets we prepared in this study can avoid extensive CYP3A4 metabolism and P-gp-mediated efflux by releasing tacrolimus in the upper part of the small intestine, promote the drug absorption, and further enhance the bioavailability of SME. Both SME, which increased drug solubility, and gastroretention technology, which prolonged the time that the drug remains in the upper part of the gastrointestinal tract, are responsible for the enhanced bioavailability of tacrolimus.

In conclusion, the current study demonstrates that a selfmicroemulsifying, swellable and bioadhesive gastroretentive delivery system, which has great potential to reduce the blood concentration fluctuations and increase the overall bioavailability of the model drug tacrolimus, has been successfully developed. The presence of highly swellable and strongly bioadhesive polymers within the developed systems provided rapid swelling and significant bioadhesive force. Soluble mannitol made the matrix more liable to erosion, which resulted in drug release in a predetermined manner by varying the mannitol concentration. The drug release was characterized by a substantial zero-order profile, which was helpful in reducing blood concentration fluctuations. Complete dissolution or erosion of the formulation matrix in a timely manner is important for gastroretentive dosage forms because very slow erosion or dissolution may lead to expulsion and other gastrointestinal safety issues. The tablet we developed could completely erode within approximately $12 \mathrm{~h}$, so it would avoid the safety problems that were previously mentioned. We can come to the conclusion that PEO in combination with chitosan is a promising carrier for gastroretentive drug delivery systems and solid self-microemulsifying drug delivery systems. SME gastroretentive sustained-release tablets are potential vehicles for drugs with poor solubility and a narrow absorption window. Moreover, it possesses broad prospects for industrial application.

\section{Acknowledgements}

We are grateful to DOW Chemical for the generous gift of PEO WSR N60K and to the ISP Corporation for kindly providing PVP K90.

\section{Author contribution}

This research was designed by Yong GAN and Xin-xin ZHANG. The experiments were performed by Yan-ping WANG. The manuscript was written by Yan-ping WANG and Xin-xin ZHANG.

\section{References}

1 Yamashita K, Nakate T, Okimoto K, Ohike A, Tokunaga Y, Ibuki R, et al. Establishment of new preparation method for solid dispersion formulation of tacrolimus. Int J Pharm 2003; 267: 79-91.

2 Kino T, Hatanaka H, Hashimoto M, Nishiyama M, Goto T, Okuhara M, et al. FK 506, a novel immunosuppressant isolated from a Streptomyces I. Fermentation, isolation and physico-chemical and biological characteristics. J Antibiot 1987; 42: 1249-55.

3 Plosker GL, Foster RH. Tacrolimus-a further update of its pharmacology and therapeutic use in the management of organ transplantation. Drugs 2000; 59: 323-89.
4 Borhade V, Nair H, Hegde D. Design and evaluation of self-microemulsifying drug delivery system (SMEDDS) of tacrolimus. AAPS PharmSciTech 2008; 9: 13-21.

5 Abdalla A, Klein S, Mader K. A new self-emulsifying drug delivery system (SEDDS) for poorly soluble drugs: characterization, dissolution, in vitro digestion and incorporation into solid pellets. Eur J Pharm Sci 2008; 35: 457-64.

6 Gursoy RN, Benita S. Self-emulsifying drug delivery systems (SEDDS) for improved oral delivery of lipophilic drugs. Biomed Pharmacother 2004; 58: 173-82.

7 Abdalla A, Mader K. Preparation and characterization of a selfemulsifying pellet formulation. Eur J Pharm Biopharm 2007; 66: 220-6.

8 Nazzal S, Khan MA. Controlled release of a self-emulsifying formulation from a tablet dosage form: stability assessment and optimization of some processing parameters. Int J Pharm 2006; 315: 110-21.

9 Patil P, Joshi P, Paradkar A. Effect of formulation variables on preparation and evaluation of gelled self-emulsifying drug delivery system (SEDDS) of ketoprofen. AAPS PharmSciTech 2004; 5: e42.

10 Joseph S, inventors; AluhaRx Inc., assignee. Solid self-emulsifying dosage form for improved delivery of poorly soluble hydrophobic compounds and the process for preparation there of. US Patent 10252158. 2002 Sep 23.

11 Tang B, Cheng G, Gu JC, Xu CH. Development of solid self-emulsifying drug delivery systems: preparation techniques and dosage forms. Drug Discovery Today 2008; 13: 606-12.

12 Serratoni M, Newton M, Booth S, Clarke A. Controlled drug release from pellets containing water-insoluble drugs dissolved in a selfemulsifying system. Eur J Pharm Biopharm 2007; 65: 94-8.

13 Balakrishnan P, Lee BJ, Oh DH, Kim JO, Hong MJ, Jee JP, et al. Enhanced oral bioavailability of dexibuprofen by a novel solid selfemulsifying drug delivery system (SEDDS). Eur J Pharm Biopharm 2009; 72: 539-45.

14 Nazzal S, Nutan M, Palamakula A, Shah R, Zaghloul AA, Khan MA. Optimization of a self-nanoemulsified tablet dosage form of ubiquinone using response surface methodology: effect of formulation ingredients. Int J Pharm 2002; 240: 103-14.

15 Tuleu C, Newton M, Rose J, Euler D, Saklatvala R, Clarke A, et al. Comparative bioavailability study in dogs of a self-emulsifying formulation of progesterone presented in a pellet and liquid form compared with an aqueous suspension of progesterone. J Pharm Sci 2004; 93: 1495-502.

16 Tamura S, Tokunaga Y, Ibuki R, Amidon GL, Sezaki H, Yamashita S. The site-specific transport and metabolism of tacrolimus in rat small intestine. J Pharmacol Exp Ther 2003; 306: 310-6.

17 Venkataramanan R, Swaminathan A, Prasad T, Jain A, Zuckerman $\mathrm{S}$, Warty $\mathrm{V}$, et al. Clinical pharmacokinetics of tacrolimus. Clin Pharmacokinet 1995; 29: 404-30.

18 Holm P, Norling T, Lademann AM, inventors; LIFECYCLE PHARMA A/S, assignee. Once daily oral dosage form comprising tacrolimus. Patent W02008/145143. 2008 May 30.

19 Kagayama A, Tanimoto S, Fujisaki J, Kaibara A, Ohara K, Iwasaki K, et al. Oral absorption of FK506 in rats. Pharm Res 1993; 10: 1446-50.

20 Shigeki T, Atsuo O, Rinta I, Gordon L, Shinji Y. Tacrolimus is a class II low-solubility high-permeability drug: the effect of P-glycoprotein efflux on regional permeability of tacrolimus in rats. J Pharm Sci 2002; 91: 719-29.

21 Streubel A, Siepmann J, Bodmeier R. Gastroretentive drug delivery systems. Expert Opin Drug Deliv 2006; 3: 217-33.

22 Strubing S, Abboud T, Contri RV, Metz H, Mader K. New insights on poly(vinyl acetate)-based coated floating tablets: Characterisation 
of hydration and $\mathrm{CO}_{2}$ generation by benchtop MRI and its relation to drug release and floating strength. Eur J Pharm Biopharm 2008; 69: 708-17.

23 Ramji AKA, Chandra SRG, Prabhakar RV. Formulation and evaluation of swellable and floating gastroretentive ciprofloxacin hydrochloride tablets. AAPS PharmSciTech 2009; 10: 220-6.

24 Parikh DC, Amin AF. In vitro and in vivo techniques to assess the performance of gastro-retentive drug delivery systems: a review. Expert Opin Drug Deliv 2008; 5: 951-65.

25 Gusler G, Berner B, Chau M, Berner B, inventors; Depomed, Inc, assignee. Optimal polymer mixtures for gastric. Patent AU2002337974. 2002 Oct 22.

26 Wu N, Wang LS, Tan DCW, Moochhala SM, Yang YY. Mathematical modeling and in vitro study of controlled drug release via a highly swellable and dissoluble polymer matrix: polyethylene oxide with high molecular weights. J Control Release 2005; 102: 569-81.

27 Mahalingam R, Jasti B, Birudaraj R, Stefanidis D, Killion R, Alfredson $\mathrm{T}$, et al. Evaluation of polyethylene oxide compacts as gastroretentive delivery systems. AAPS PharmSciTech 2009; 10: 98-103.

28 Waterman KC. A critical review of gastric retentive controlled drug delivery. Pharm Dev Technol 2007; 12: 1-10.

29 Klausner EA, Lavy E, Friedman M, Hoffman A. Expandable gastroretentive dosage forms. J Control Release 2003; 90: 143-62.

30 Werle M, Bernkop SA. Thiolated chitosans: useful excipients for oral drug delivery. J Pharm Pharmacol 2008; 60: 273-81.
31 Chambin O, Jannin V, Champion D, Chevalier C, Rochat-Gonthier MH, Pourcelot Y. Influence of cryogenic grinding on properties of a selfemulsifying formulation. Int J Pharm 2004; 278: 79-89.

32 Constantinides PP. Lipid microemulsions for improving drug dissolution and oral absorption: physical and biopharmaceutical aspects. Pharm Res 1995; 12: 1561-72.

33 Li HT, Hardy RJ, Gu XC. Effect of drug solubility on polymer hydration and drug dissolution from polyethylene oxide (PEO) matrix tablets. AAPS PharmSciTech 2008; 9: 437-43.

$34 \mathrm{Kim} \mathrm{CJ}$. Effects of drug solubility, drug loading, and polymer molecular weight on drug release from Polyox ${ }^{\circledR}$ tablets. Drug Dev Ind Pharm 1998; 24: 645-51.

35 Shah NH, Carvajal MT, Patel Cl, Infeld MH, Malick AW. Self-emulsifying drug delivery systems (SEDDS) with polyglycolized glycerides for improving in vitro dissolution and oral absorption of lipophilic drugs. Int J Pharm 1994; 106: 15-23.

36 Hauss DJ, Fogal SE, Ficorilli JV, Price CA, Roy T, Jayaraj AA, et al. Lipidbased delivery systems for improving the bioavailability and lymphatic transport of a poorly water-soluble LTB4 inhibitor. J Pharm Sci 1998; 87: 164-9.

37 Fischl MA, Richman DD, Flexner C, Para MF, Jaubrich R, Karim A, et al. Phase I/II study of the toxicity, pharmacokinetics, and activity of the HIV protease inhibitor SC-52151. J Acquir Immune Defic Syndr Hum Retrovirol 1997; 15: 28-34. 